\title{
Gulf War syndrome - has it gone away?
}

\author{
Mark Tarn, Neil Greenberg \& Simon Wessely
}

\begin{abstract}
Gulf War syndrome' was a phrase coined after the 1991 Gulf War. This article looks at the variety of hypotheses that have been put forward about the origins of the concept and the studies attempting to characterise the health manifestations of Gulf service and the lasting effects on veterans. It also serves to bring readers up to date with research on the present deployment in Iraq. Finally, consideration is given to how Gulf War syndrome compares with the rich historical literature of post-conflict medical syndromes and how sociological factors may interact with symptom attribution in veterans.
\end{abstract}

'Yours is a society which cannot accept 10,000 dead in one battle.'

Saddam Hussein, President of Iraq 1979-2003

In 1991 a coalition of Allied Nations, including British and US troops, deployed to the Persian Gulf region. Although the war-fighting phase of the 1991 conflict was short and resulted in minimal casualties, few can have failed to notice the saga of 'Gulf War syndrome' which followed the conflict. The nature, and indeed existence, of Gulf War syndrome has been the subject of heated debates in the public arena for the past 15 years. This article reviews the history of Gulf War syndrome and brings the story up to date, by looking at the current deployment to Iraq.

\section{The first Gulf conflict}

In August 1990, Iraqi troops conquered and annexed Kuwait. The Iraqi president Saddam Hussein was reportedly furious with Kuwait for driving down world oil prices by overproduction. In one fell swoop, he held almost half of the world's oil reserves and had troops ominously placed along the Saudi border.

The international community's response was to assemble a coalition of military forces from the USA (697000 troops committed), the UK (53500), France (25000) and over 30 other nations, including Saudi Arabia, Egypt, Canada and Australia.
In January 1991, the coalition forces began an intense bombardment of Iraqi positions and, 5 weeks later, on 24 February, the ground war began. It lasted only 4 days and was viewed as a resounding military success.

The campaign was also seen as a great triumph for the military medical services. Traditionally, deployments in such conditions have yielded significant numbers of so-called 'disease non-battle injury' casualties such as those affected by heat illness. There is no evidence of any deaths from such factors among US or British troops (Hyams et al, 1995).

But, as we know, the medical story did not end there.

\section{The birth of a syndrome?}

Shortly after the cessation of hostilities, reports started to emerge from the USA of clusters of unusual illnesses occurring in Gulf War veterans. The media coverage concerned itself with two main reported phenomena: rare diseases in previously fit veterans and an increase in birth defects in veterans' children. There was considerable public interest in these reports, which led to enormous media coverage and the coining of the phrase 'Gulf War syndrome', although it is not clear by whom. As a result of these stories the USA, and latterly the UK, began to conduct formal epidemiological research.

\footnotetext{
Mark Tarn is a specialist registrar in liaison psychiatry at King's College Hospital, London, and is also a serving Army officer. Previously he was a military general practitioner and served as a GP tutor in the Army's air assault brigade. His interests include the interface between primary and secondary care. Neil Greenberg is a senior lecturer at King's College London and is also a military consultant psychiatrist in the Royal Navy (King's Centre for Military Health Research, 3rd Floor, Weston Education Centre, Cutcombe Road, London SE5 9RJ, UK. Email: sososanta@aol.com). He has a keen interest in organisational mental health, traumatic stress and in psychological health in military personnel. Simon Wessely is a Professor of Epidemiology and Liaison Psychiatry at the Institute of Psychiatry, London. His research interests are in the grey areas between medicine and psychiatry, clinical epidemiology, psychiatric injury and military health. He is the civilian consultant advisor to the Army; this is an honorary and unpaid role.
} 


\section{The first studies}

The first response was the setting up of disease registers in the USA: any US Gulf veteran was able to attend a designated clinic and receive a comprehensive health assessment. The UK followed, with the establishment of the Gulf War veterans' Medical Assessment Programme. Eventually, over 100000 veterans attended these programmes. Most attended in the USA, but over 3000 were seen in the UK. Case registers like this are not random samples of the population, but given the numbers involved, they would have sufficient power to detect any major increase in a well-recognised illness or disease. In fact, no such pattern was found, either a gross excess of known disease or evidence of a new condition or illness. This should be contrasted, for example, with how swiftly the medical community was able to detect an unusual pattern of disease in gay men in San Francisco, leading to the identification of AIDS. Instead, the largest diagnostic category was medically unexplained symptoms and syndromes (King's Centre for Military Health Research, 2006).

However, those that attended the programme were self-selecting and so the data must be interpreted cautiously. But if Gulf War service was associated with a new identifiable disease or a substantial increase in the occurrence of a rare condition, this should have been demonstrated. Neither was apparent in the results (Gray et al, 2004). However, registry data are insufficient to detect small increases in known diseases or, alternatively, a subtle change in symptom clustering - in other words, a true Gulf War syndrome.

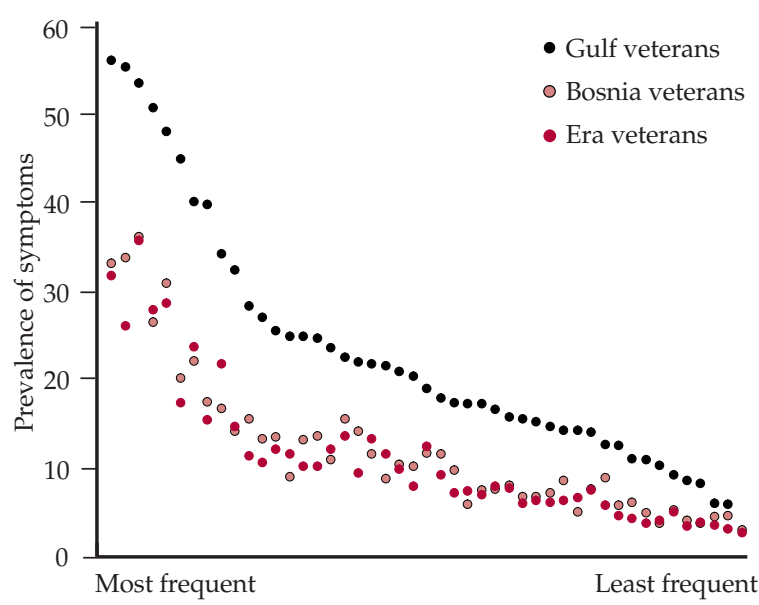

Fig. 1 The Gulf health effect. Era veterans, nondeployed personnel of Gulf War era. After Unwin $e t$ al (1999), with permission.

\section{Cancer and mortality}

The media on both sides of the Atlantic have suggested that there has been an increase in mortality rates in Gulf War veterans. Comprehensive analyses of both the US and UK Gulf cohorts have shown no such increase in either group other than a rise in the rate of accidental death (US and UK) and suicide (US only), an observation often made in the aftermath of other conflicts (Kang \& Bullman, 1996; MacFarlane et al, 2000), possibly linked to an increase in risk-taking behaviour. Furthermore, UK research undertaken in Manchester has failed to show an increase in cancer rates among UK veterans of the conflict (King's Centre for Military Health Research, 2006).

\section{The Gulf War health effect}

It was the Iowa Persian Gulf Study Group (1997) that was the first team to identify increased rates of symptom reporting in a Gulf cohort. Symptomdefined conditions, including chronic fatigue syndrome, depression and post-traumatic stress disorder (PTSD), were all elevated.

The first UK systematic epidemiological study was at King's College London. There a comprehensive study was conducted of 4246 randomly selected UK veterans of the Gulf War, drawn from all three armed services, with similar numbers of non-deployed personnel of the same era, and with an active-duty control group who had served, some years later, in the Bosnian conflict. The results showed that the Gulf veterans were between two and three times more likely to report each and every one of the 50 somatic symptoms that were inquired about (Unwin et al, 1999). Whatever the symptom, compared with the Bosnian control group and the non-deployed cohort (the so-called era group), the rate was at least twice as high in the Gulf cohort. Health perception was decreased in the Gulf cohort, yet physical functioning was only very slightly different and still above expected non-military norms. Thus, despite still having overall good physical function, the Gulf veterans experienced more symptoms, endorsed more conditions and felt worse than either the nondeployed cohort or those deployed to an unpleasant and stressful Bosnian theatre of operations.

Figure 1 illustrates these findings. Each data point represents an individual physical symptom. To the left are common symptoms such as fatigue or headache; to the right are unusual symptoms such as a lump in throat, night sweats or frequent urination. It is clear that there is no difference between those deployed to Bosnia and those in the military 
Box 1 Gulf War service and related health effects

- An increase in self-reported ill health among UK Gulf veterans is well demonstrated

- There is no unique and readily characterised 'Gulf War syndrome'

- Other coalition forces, such as those of the USA and Canada, report similar findings

- There is no association with an increase in cancer prevalence

- An increase in mortality due to accidents has been recorded in UK and US veterans

- Increase in mortality due to suicide has been recorded in US but not in UK veterans

in general in 1991 who did not deploy to the Gulf at that time. It is striking that the Gulf cohort is different. But of equal interest is that the shape of the curve between the Gulf and the control groups does not differ, suggesting that no specific symptom is linked with Gulf service. Instead, personnel who deployed to the Gulf just report more of every symptom that they were asked about (King's Centre for Military Health Research, 2006).

These have not been isolated findings (Stretch et al, 1995; Kang et al, 2000). A review by Barrett et al (2003) concluded that Gulf War veterans report two to three times the rates of common symptoms reported by their non-deployed colleagues. Other studies have found impaired health perception and quality of life in military personnel that deployed to the Gulf, compared with those that did not (Proctor et al, 2001; Voelker et al, 2002). A summary of all these findings can be seen in Box 1 .

Investigators did find an increase in seborrhoeic dermatitis (King's Centre for Military Health Research, 2006), but this has received little comment or indeed media interest. Also, a large US study using multiple methods of data collection has reported 40 cases of amyotrophic lateral sclerosis. TheUS government has considered this a significant enough increase to declare the disease serviceattributable (Horner et al, 2003). However, there remains good reason to believe that the excess is due to an ascertainment bias, in which greater efforts were made to find cases in Gulf veterans as opposed to controls, and also to an unusually low rate of amyotrophic lateral sclerosis in those controls. Overall, there has not been an increase in mortality due to neurological disease, which would be expected as amyotrophic lateral sclerosis is ultimately fatal. The condition still remains rare in the veterans and cannot explain the overall increase in symptomatology in Gulf veterans.

\section{Psychological sequelae}

Since an increase in physical symptoms among Gulf War veterans is a consistent finding, it is of little surprise that many of the participants examined in the studies also fulfilled the diagnostic criteria for depression, anxiety and PTSD. Just as they also fulfilled the criteria for chronic fatigue syndrome, multiple chemical sensitivity and irritable bowel syndrome. But when these peoplewere interviewed using validated gold-standard instruments it became apparent that many did not have formal psychiatric disorders. Numerous research studies into Gulf veterans have concluded that although the rate of true psychiatric disorders had doubled among them, the absolute burden of disorder, as a result of formal psychiatric disorder, remained low: PTSD, for example, had a prevalence of 3\% (King's Centre for Military Health Research, 2006). So although personnel were twice as likely to have PTSD if they went to the Gulf (Stimpson et al, 2003), most Gulf veterans, even those with increased levels of physical symptoms, did not have mental health disorders.

Therefore, psychiatric disorders per se cannot wholly account for the Gulf War health effect, although clearly such disorders are still a cause of difficulty for those who suffer from them and no doubt also for their families. These findings are summarised in Box 2.

\section{Limitations of the epidemiological studies}

The epidemiological studies that have investigated Gulf War syndrome have all used selfreporting measures and these tend to have a poor correlation with findings on clinical physical examination (McCauley et al, 1999). For instance, when 'medically unexplained syndromes', which are characterised by symptoms very similar to those of Gulf War syndrome, have been

Box 2 Gulf War service and the psychological sequelae

- Increase in depressive and neurotic symptoms in veterans

- Many do not meet the diagnostic criteria for a formal psychiatric illness

- Rate of disorders (e.g. PTSD) is doubled but still remains low overall

- It is unlikely that the Gulf health effect is due to multiple psychiatric disorders 
investigated in the community, where they are very common, fewer than 1 in 5 are found to have a discrete biomedical explanation (Kroenke \& Mangelsdorff, 1989). Thus, it is not possible to assume that reporting of symptoms is closely linked with having a diagnosable disease or disorder (Mayou et al, 1995).

Recall and participant biases are important considerations when examining the evidence concerning Gulf War syndrome. The literature confirms that the recall of military hazards is influenced moreby a person's current psychological health than it is by fact (King's Centre for Military Health Research, 2006). Indeed, a study of the medical records of a group who were supposedly prepared for deployment to the Gulf (in terms of vaccinations) but did not actually deploy revealed that less than $1 \%$ of those who recalled having received a biological warfare vaccine had done so (Greenberg et al, 2003). What can never be controlled for is that the personnel who did deploy to the Gulf will always remember that they were there. Consequently, participant bias is likely to operate and those who deployed may have an increased likelihood of attributing their symptoms to their Gulf deployment.

\section{Can we use the phrase 'Gulf War syndrome'?}

The numerous research studies already cited have not yielded a unique constellation of symptoms and signs that can be identified as a Gulf War syndrome. Furthermore, the symptoms experienced by veterans also occur elsewhere, without an association with a Gulf deployment (Wegman et al, 1998).

There is one notable detractor from this position, the US epidemiologist Robert Haley. His group has claimed evidence of both central and peripheral nerve damage in Gulf veterans, which they attributed to exposure to a combination of chemical weapons and/or pesticides (Haley et al, 1997). His study has been criticised as considering only a single reserve engineering unit, having a poor response rate and being conducted without a control group. Furthermore, expert review panels have not been convinced by either the medical evidence or the suggestion of exposure to chemical weapons. Other studies (King's Centre for Military Health Research, 2006) failed to find evidence of significant damage to the peripheral nervous system, making exposure to organophosphate pesticides an unlikely cause of ill health.

What we believe is that there is substantial evidence to suggest the existence of an identifiable
Gulf health effect but that effect does not amount to a discrete disorder or indeed syndrome. However, numerous papers have shown beyond reasonable doubt that there are substantial numbers of veterans labelled with Gulf War syndrome who have identifiable problems; reported prevalence rates range from 20 to 30\% (Fukuda et al, 1998; Steele, 2000; Cherry et al, 2001; Gray et al, 2002). Furthermore, we do not consider that the reporting of symptoms is, in the main, a result of attempts to procure financial benefit. The UK's war pension system does not require a formal diagnosis, simply an opinion on the level of disability, from whatever cause. Even though many Gulf veterans have received monetary recompense for their disabilities, research evidence strongly suggests that most Gulf veterans who were ill in 1996 were still unwell in 2001 (King's Centre for Military Health Research, 2006).

In 2004, two important reports concerning Gulf War illnesses were published. In the USA, the Department of Veterans Affairs established the Research Advisory Committee on Gulf War Veterans' Illnesses and its report detailed that the Gulf War illnesses were probably caused by neurotoxins and that more research was needed. The UK hosted an unofficial public inquiry on Gulf War illnesses chaired by Lord Lloyd of Berwick. The inquiry was privately funded and the names of those funding it have not been made public. It concluded that the term Gulf War syndrome is valid and that payments should be made to those suffering from it (Lloyd et al, 2004). Interestingly, the panel of experts assembled did not have any additional research material to consider other than that already widely reviewed.

In 2005, the UK's Ministry of Defence accepted the phrase 'Gulf War syndrome', for the purpose of awarding war pensions, with the caveat that the term was basically an umbrella phrase covering the various clinical presentations and outcomes.

In conclusion, although it is clear that there is no unique Gulf War syndrome, the term itself is here to stay.

\section{Who is at risk?}

It is interesting to note that the Gulf War health effect is not associated with duration of combat exposure. The predictors of ill health tend to be nonspecific. For example, having a lower rank (King's Centre for Military Health Research, 2006), which is highly correlated with educational achievement, is firmly associated with ill health (Wolfe et al, 1998; Ford et al, 2001). Rank is also a proxy marker of socio-economic status, which has always been recognised as a predictor of health. 
Some studies have found differences between the armed services. For example, a US study has found that its Naval personnel are less at risk than their Army colleagues (Steele, 2000); but this has not been found in the UK. Likewise, prevalence rates appear unrelated to an individual's job or task in the Gulf conflict. These are important findings in terms of a possible unifying aetiology. Several other US studies have reported that reservists and women are at increased risk (Gray et al, 2002; Carney et al, 2003), suggesting a possible predisposition; but again, this was not the case for UK personnel. However, the UK armed forces used far fewer reservists and women during the conflict, which might explain these differences.

\section{Causative agents - the usual suspects?}

As time moves on, it is looking more likely that we will never achieve a precise explanation for the increase in ill health seen in veterans of the 1991 Gulf War. It is likely that a combination of factors was present; some have achieved more notoriety than others. Box 3 summarises those considered here.

\section{Medical countermeasures}

Can the effects on veterans' health be accounted for by exposure to biological hazards in the Gulf? At the time, there was a significant threat of deployment of chemical and biological warfare weapons, and this was highly stressful for personnel involved. Media reports have suggested that the specific medical countermeasures that were taken, such as the anthrax vaccinations, caused health problems. Research in this area is contradictory. It is accepted that there is a link between receiving multiple vaccinations in general, and those against chemical and biological warfare agents in particular, and the persistence of

Box 3 Gulf War syndrome and postulated aetiological factors

- Vaccinations against anthrax

- Multiple vaccinations undertaken in an operational theatre

- Use of pyridostigmine bromide tablets

- Depleted uranium munitions

- Organophosphate pesticides

- Burning oil-well fumes

- Stress symptoms, despite controlling for obvious confounders. Detailed investigations have failed to confirm that this link is immunologically mediated (King's Centre for Military Health Research, 2006). There could be an unknown confounder at play, such as the stress of deploying on a major war footing, or receiving some vaccinations in the theatre of operations. The finding that multiple vaccinations in other contexts, including deployment to Bosnia, were not associated with any increase in experience of symptoms suggests some interaction between multiple vaccinations and active service deployment to the Gulf (Unwin et al, 1999; Hotopf et al, 2000; Cherry et al, 2001).

Another often-mentioned medical countermeasure was the use of pyridostigmine bromide tablets as a prophylactic against the effects of some chemical weapons. However, Canada sent three ships to the Gulf, only two of which used pyridostigmine bromide prophylaxis, yet the rate of illness was the same on all three ships (Anonymous, 1998).

\section{Depleted uranium}

Depleted uranium is used in munitions such as tank shells, because of its high density. It is often cited as a possible cause of ill health in Gulf personnel. Those most likely to come into contact with depleted uranium would have been troops working in or around armoured vehicles. But, as we have already discussed, there is no link between the role an individual veteran fulfilled and whether or not they develop symptoms.

A US research group has identified and studied a small group of US Gulf veterans that were definitely exposed to depleted uranium in the form of shrapnel fragments from a friendly fire incident. Despite intensive investigation and monitoring for over 10 years, there is no clear-cut evidence of tissue damage in spite of persistently elevated urinary uranium levels (McDiarmid et al, 2004). The research team has identified some minor immune system changes and subtle changes in cognitive function, but have concluded that these findings are of little or no clinical relevance and certainly do not explain Gulf War syndrome phenomena.

\section{Pesticides}

During the Gulf campaign, organophosphate pesticides were successfully used to decrease the threat of disease from insect vectors. Organophosphate pesticide toxicity is best studied by trying to identify the effects these pesticides have on the nervous system. 
Detailed studies of the peripheral nervous system in both US and UK veterans have failed to find evidence of neuropathy (Bourdette et al, 2001). Of particular relevance is a normal finding on sensitive single-fibre electromyography (EMG), which is strong evidence against any chronic peripheral nerve damage (King's Centre for Military Health Research, 2006). A large US epidemiological survey of Gulf War veterans and their families came to the same conclusion (Davis et al, 2004). There is also little evidence of central nervous system damage, as indicated by a lack of objective (as opposed to subjective) evidence of neuropsychological deficits (King's Centre for Military Health Research, 2006).

\section{Fumes from burning oil wells}

As pointed out in the Lloyd Report (Lloyd et al, 2004), only a small proportion of military personnel were exposed to fumes from the oil-fuelled fires. These were predominantly those garrisoned in Kuwait during the post-war clean-up period. Clearly this cannot account for the majority with symptoms who were never exposed. Interestingly, work looking specifically at monitoring polycyclic aromatic hydrocarbon biomarkers (PAHs), has shown higher ambient atmospheric levels of PAHs for US troops stationed in Germany than those deployed to Kuwait (Poirier et al, 1999).

\section{Psychological stress}

Could symptoms in veterans be a result of psychological stressors arising from anxieties about weapons of mass destruction and the media interest? There is a strong contextual flavour to Gulf War syndrome and the various elements at play have been extensively explored by Iversen et al (2007). But it should be remembered that, historically, there have been other syndromes that seemed to be bound to military service.

\section{War syndromes}

History has many examples of post-conflict ill health syndromes (Hyams et al, 1996). Interpretable medical records and accounts commence in the middle of the 19th century, but from then onwards the literature contains clinical descriptions of ex-servicemen with conditions that do show considerable similarities to the narratives of Gulf War veterans (Box 4).

Other research that has examined this matter has come to the same conclusion: when military personnel go to war, some come back and report feeling ill. For instance, Jones \& Wessely conducted
Box 4 Historical syndromes described in association with military service

- Soldiers' heart (effort syndrome)

- Shell shock

- Neurasthenia

- Agent Orange syndrome (in the Vietnam War)

- Post-traumatic stress disorder

a systematic study of UK war pension files from the Boer War, the First and Second World Wars, and ending with clinical files from the Gulf War Medical Assessment Programme (King's Centre for Military Health Research, 2006). The results reveal that post-conflict syndromes that show considerable similarities to Gulf War illnesses have been reported after all the major conflicts involving the British armed forces.

As noted above, it is of interest that the classic psychological post-war syndrome, PTSD, is elevated in UK Gulf veterans, but not to the extent that could explain the overall increase in ill health (Ismail et al, 2002). The relative risk was very similar to that in an overall meta-analysis of nine studies of psychiatric disorder in Gulf War veterans, which reported an odds ratio of 3.2 for the risk of PTSD (Stimpson et al, 2003) but the overall rate of PTSD in veterans was low at 3\%.

The medical literature is also peppered with medically unexplained symptoms with similarities to the Gulf War health effect. These include chronic fatigue syndrome, total allergy syndrome, dental amalgam disease and sick building syndrome.

The clinical manifestations of service in the 1991 Gulf War may well be influenced by veterans' lack of trust in government official comments on aspects of the conflict. There are similarities between the experiences of Gulf War veterans and those of Vietnam veterans (King's Centre for Military Health Research, 2006). The perceived government misinformation regarding Agent Orange was used to claim similar cover-ups and conspiracies, as was the Cold War legacy of experiments carried out on service personnel, often without consent. Governments on either side of the Atlantic have made misinformed statements on Gulf issues. For example, the US government misjudged the Khamisayah incident (an Iraqi arms dump that was thought to have held chemical weapons), and the UK government made an inadvertently inaccurate statement to Parliament about the use of organophosphate pesticides. Both episodes led to further suspicion and occasional paranoia, neither of which has helped the situation of Gulf veterans. 


\section{Have treatments been successful?}

There has not been a consensus on the most effective therapies. Cognitive-behavioural therapy has been tried, following approaches used for similar medically unexplained symptoms such as chronic fatigue syndrome. In 2003, the US Department of Defense and the Veteran's Administration carried out a large trial comparing cognitive-behavioural therapy, graded exercise therapy and a combination of both. The trial involved 1092 symptomatic Gulf veterans. The interventions achieved littleimprovement in their symptoms (Donta et al, 2003).

\section{What has been the prognosis of those with Gulf-related illness?}

Asubstantial number of Gulf War veterans continue to report poor health. Hotopf et al (2003) followed up at 4 years a cohort of people who believed they had Gulf War syndrome. They remained unwell, although interestingly, the health gap between the Gulf veterans and the non-deployed personnel of the same era appeared to be narrowing.

\section{Is there an Iraqi war syndrome?}

The UK again sent military personnel to the Gulf in 2003, and has maintained troops there ever since. The UK's Ministry of Defence has been funding substantial investigations into the health effects on those troops deployed. The King's Centre for Military Health Research (KCMHR) has continued to conduct in-depth studies.

\section{The KCMHR studies}

The military name for the current Iraq deployment is Operation TELIC, with Op TELIC 1 being the first deployment of ground troops. After Op TELIC 1 , a cohort study was assembled at KCMHR. This time there were only two groups, those that had served on Op TELIC and a single control group from the rest of the armed forces. Concerns about possible health effects in reservists meant that they were over-sampled in order that smaller changes in their health could be detected (King's Centre for Military Health Research, 2006).

The results were surprising (Fig. 2). There has not been the increase in somatic symptoms that was clearly apparent in the earlier Gulf War study.

So, currently there is no evidence of a repeat of a 'Gulf War syndrome' arising in personnel returning from Iraq. Given that in both conflicts the UK armed forces used depleted uranium munitions,
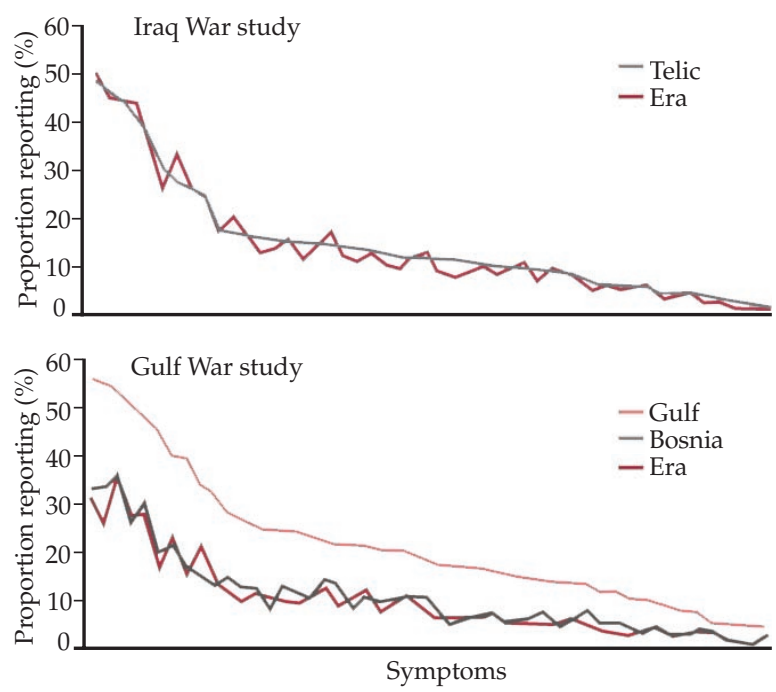

Fig. 2 Comparison of health effects on veterans of the 1991 Gulf War and of the Iraq War. Telic, current Iraq deployment; Era, non-deployed personnel of Gulf War era. After King's Centre for Military Health Research (2006), with permission.

were given anthrax vaccine and pyridostigmine bromide tablets, and used pesticides, yet there was only a Gulf War health effect in the earlier and not the later conflict, it follows that these factors are unlikely to be the cause of Gulf-related ill health. Also, since the current war in Iraq is proving to be a more long-lasting and difficult engagement, simplistic explanations of Gulf-related illness as a manifestation of stress seems unlikely as the theatre of operations is now considerably more hostile and more stressful.

In terms of mental health problems, researchers at KCMHR also found that there was no increase in psychiatric disorders after Op TELIC 1 among regular personnel, but there was among reservists, when compared with the rest of the UK armed forces (King's Centre for Military Health Research, 2006). Reservists were twice as likely to have symptoms suggestive of common mental health problems and six times more likely to have symptoms suggestive of PTSD. The explanation for this is not readily apparent, but it may be partly explained by the way reservists are rapidly reintegrated back into civilian life after a deployment. When these results were published, the Ministry of Defence announced that reservists would be entitled to access to military mental healthcare for up to 2 years after deployment and not be dependent on National Health Service facilities.

In contrast, studies show a much higher rate of PTSD in US troops than in UK armed forces (Hoge et al, 2004). There are differences between the US 
and UK deployments that may help to explain this. The USA deploy their troops for a year at a time, sometimes more, whereas UK military personnel usually have 4-6 month tours of duty. The US forces have undertaken more fighting and have taken more physical casualties, and this lends itself to more psychological injuries. Other factors may also be at play, for instance UK military personnel tend to be older than their US equivalents.

\section{The future}

It seems unlikely that any single cause of the Gulf War health effect will ever be discovered, and it is heartening that for whatever reasons the UK's Iraq War veterans do not as yet seem to be experiencing a repeat of the Gulf War syndrome. We say 'as yet' because no one knows when the Gulf health effect was first detectable, only that it was present a minimum of 5 years after the conflict. Research and health surveillance must continue, not least as events on the ground continue to unfold. We can also suggest that the Ministry of Defence will need to ensure that it keeps its personnel properly briefed about potential hazards, so that a future attribution of ill health will not be to service in a war zone, but perhaps to more conventional aetiological factors.

\section{Declaration of interest}

M.T. and N.G. are serving regular officers in the Defence Medical Services. However, this article has not been subject to any amendment or alteration by the Ministry of Defence. S.W. has received funding from the Ministry of Defence to undertake research into issues affecting military personnel.

\section{References}

Anonymous (1998) Health Study of Canadian Forces Personnel Involved in the 1991 Conflict in the Persian Gulf. Goss Gilroy.

Barrett, D. G., Doebbeling, B. N., Clauw, D. J., et al (2003) Prevalence of symptoms and symptom-based conditions among Gulf War veterans: current status of research findings. Epidemiological Reviews, 24, 218-227.

Bourdette, D., McCauley, L., Barkhuizen, A., et al (2001) Symptom factor analysis, clinical findings and functional status in a population-based case control study of Gulf War unexplained illness. Journal of Occupational and Environmental Medicine, 43, 1026-1040.

Carney, C. P., Sampson, T. R., Voelker, M., et al (2003) Women in the Gulf War: combat experience, exposures, and subsequent health care use. Military Medicine, 168, 654-651.

Cherry, N., Creed, F., Silman, A., et al (2001) Health and exposures of United Kingdom Gulf war veterans. Part 1: The pattern and extent of ill health. Occupational and Environmental Medicine, 58, 291-298.

Davis, L., Murphy, F., Alpern, R., et al (2004) Clinical and laboratory assessment of distal peripheral nerves in Gulf War veterans and spouses. Neurology, 63, 1070-1077.
Donta, S. T., Clauw, D. J., Engel, C. C., et al. (2003) Cognitive behavioural therapy and aerobic exercise for Gulf War veterans' illnesses. A randomized controlled trial. JAMA, 289, 1396-1404.

Ford, J., Campbell, K., Storzbach, D., et al (2001) Post-traumatic stress symptomatology is associated with unexplained illness attributed to Persian Gulf War military service. Psychosomatic Medicine, 63, 842-849.

Fukuda, K., Nisenbaum, R., Stewart, G., et al (1998) Chronic multisymptom illness affecting air force veterans of the gulf war. JAMA, 280, 981-988.

Gray, G., Reed, R., Kaiser, K., et al (2002) Self reported symptoms and medical conditions among 11,868 Gulf War Era veterans. American Journal of Epidemiology, 155, 1033-1044.

Gray, G., Kang, H., Graham, J., et al (2004) After more than 10 years of Gulf War veteran medical examinations, what have we learned? American Journal of Preventive Medicine, 26, 443452.

Greenberg, N., Iversen, A., Hull, L., et al (2003) Vaccination records in Gulf War veterans. Journal of Occupational and Environmental Medicine, 45, 219.

Haley, R., Kurt, T. \& Hom, J. (1997) Is there a Gulf War syndrome? Searching for syndromes by factor analysis of symptoms. JAMA, 277, 215-222.

Hoge, C. W., Castro, C. A., Messer, S. C., et al (2004) Combat duty in Iraq and Afghanistan, mental health problems, and barriers to care. New England Journal of Medicine, 351, 13-22.

Horner, R., Kamins, K., Feussner, J., et al (2003) Occurrence of amyotrophic lateral sclerosis among Gulf War veterans. Neurology, 61, 742-749.

Hotopf, M., David, A., Hull, L., et al (2000) The role of vaccinations as risk factors for ill-health in veterans of the Persian Gulf War. BMJ, 320, 1363-1367.

Hotopf, M., David, A. S., Hull, L., et al (2003) Gulf war illness - better, worse, or just the same? A cohort study. BMJ, 327, 1370.

Hyams, K., Hanson, K., Wignall, F., et al (1995) The impact of infectious diseases on the health of US troops deployed to the Persian Gulf during Operations Desert Shield and Desert Storm. Clinical Infectious Diseases, 20, 1497-1504.

Hyams, K., Wignall, F. \& Roswell, R. (1996) War syndromes and their evaluation: from the US Civil War to the Persian Gulf War. Annals of Internal Medicine, 125, 398-405.

Iowa Persian Gulf Study Group (1997) Self-reported illness and health status among Persian Gulf war veterans: a populationbased study. JAMA, 277, 238-245.

Ismail, K., Kent, K., Brugha, T., et al (2002) The mental health of UK Gulf war veterans: phase 2 of a two phase cohort study. $B M J, 325,576$.

Iversen, A., Chalder, T. \& Wessely, S. (2007) Gulf war illness. Lessons from medically unexplained symptoms. Clinical Psychology Review, 27, 842-854.

Kang, H. \& Bullman, T. (1996) Mortality among U.S. veterans of the Persian Gulf War. New England Journal of Medicine, 335, 1498-1504.

Kang, H. K., Mahan, C. M. \& Murphy, F. M. (2000) Illnesses among United States veterans of the Gulf War. A population based survey of 30,000 Veterans. Journal of Occupational and Environmental Medicine, 42, 491-501.

King's Centre for Military Health Research (2006) A Ten Year Report: What Has Been Achieved by a Decade of Research into the Health of the UK Armed Forces? KCMHR (http://www. $\mathrm{kcl}$.ac.uk/kcmhr/information/reports/kcmhr/ $/ \mathrm{kcmhr}_{-} 10_{-}$ year_report.pdf).

Kroenke, K. \& Mangelsdorff, A. (1989) Common symptoms in ambulatory care: incidence, evaluation, therapy and outcome. American Journal of Medicine, 86, 262-266.

Lloyd, A., Jones, N. \& Davies, M. (2004) The Lloyd Report: Independent Public Inquiry on Gulf War Illnesses. Gulf War Illnesses Public Inquiry (http://www.lloyd-gwii.com/ report.asp).

MacFarlane, G., Thomas, E. \& Cherry, N. (2000) Mortality amongst United Kingdom Gulf War veterans. Lancet, 356, $17-21$.

Mayou, R., Bass, C. \& Sharpe, M. (1995) Overview of epidemiology, classification and aetiology. In Treatment of 
Functional Somatic Symptoms (eds R. Mayou, C. Bass \& M. Sharpe), pp. 42-65. Oxford University Press.

McCauley, L., Joos, S., Lasarev, M., et al (1999) Gulf war unexplained illnesses: persistence and unexplained nature of self-reported symptoms. Environmental Research, 81, 215-223.

McDiarmid, M. A., Squibb, K. \& Engelhardt, S. M. (2004) Health effects of depleted uranium on exposed Gulf War veterans. A 10 year follow up. Journal of Toxicology and Environmental Health Part A, 67, 277-296.

Poirier, M., Weston, A., Schoket, B., et al (1999) Polycyclic aromatic hydrocarbon biomarkers of internal exposure in US Army soldiers serving in Kuwait in 1991. Polycyclic Aromatic Compounds, 17, 197-208.

Proctor, S., Harley, R., Wolfe, J., et al (2001) Health related quality of life in Gulf War veterans. Military Medicine, 166, 510-519.

Research Advisory Committee on Gulf War Veterans' Illnesses (2004) Scientific Progress in Understanding Gulf War Veterans' Illnesses: Report and recommendations. US Department of Veterans Affairs.

Steele, L. (2000) Prevalence and patterns of Gulf war illness in Kansas veterans: association of symptoms with characteristics of person, place and time of military service. American Journal of Epidemiology, 152, 992-1002.

Stimpson, N. J., Thomas, H. V., Weightman, A. L., et al (2003) Psychiatric disorder in veterans of the Persian Gulf War of 1991. Systematic review. British Journal of Psychiatry, 182, 391-403.

Stretch, R., Bliese, P., Marlowe, D., et al (1995) Physical health symptomatology of Gulf War-era service personnel from the States of Pennsylvania and Hawaii. Military Medicine, 160, 131-136.

Unwin, C., Blatchley, N., Coker, W., et al (1999) The health of United Kingdom servicemen who served in the Persian Gulf War. Lancet, 353, 169-178.

Voelker, M., Saag, K., Schwartz, D., et al (2002) Health-related quality of life in Gulf War era military personnel. American Journal of Epidemiology, 155, 899-907.

Wegman, D., Woods, N. \& Bailar, J. (1998) Invited commentary: How would we know a Gulf War Syndrome if we saw one? American Journal of Epidemiology, 146, 704-711.

Wolfe, J., Proctor, S., Duncan Davis, J., et al (1998) Health symptoms reported by Persian Gulf War veterans two years after return. American Journal of Industrial Medicine, 33, 104113

\section{MCQs}

1 Military service in the 1991 Gulf War is associated with:

a a well-characterised and unique Gulf War syndrome

b a Gulf health effect

c an increase in cancer rates

$\mathrm{d}$ decrease in death by accidents

e increase in suicide by UK personnel.
2 The following syndromes have symptom clusters that have not been found in Gulf War veterans:

a chronic fatigue syndrome

b multiple chemical sensitivity

c irritable bowel syndrome

d dental amalgam disease

e acute polonium poisoning.

3 Studies have shown that those at increased risk of developing a Gulf War illness include:

a higher ranking personnel

b US Navy veterans

c UK veteran reservists

d US female veterans

e tank crews.

4 Post-conflict syndromes that have been described include:

a dental amalgam disease

b Agent Orange syndrome

c premenstrual syndrome

d irritable bowel syndrome

e sick building syndrome.

5 Factors that have been present in both the $1991 \mathrm{Gulf}$ War and the Iraq War include:

a depleted uranium

$b$ use of chemical weapons

c extensive vaccination programmes in the operational theatre

d use of biological weapons

e extensive oil-well fires. 